\title{
報文
}

\author{
干しシイタケの各種銘柄の形状, 遊離アミノ酸 \\ 扣よびレンチニン酸含有量について
}

\author{
奥崎政美*·佐々木弘子**·青柳康夫***.菅原龍幸** \\ ( ${ }^{*}$ 女子栄養大学栄養科学研究所 $\cdot * *$ 食品化学. ***女子栄養短期大学食品化学 $)$
}

\section{External Shapes, Free Amino Acidsand Lentinic Acid Content in Different Varieties of Dried Shiitake Mushroom(Lentinus edodes Sing.)}

\author{
Masami Okuzaki*, Hiroko Sasaki**, Yasuo Aoyagi***, Tatsuyuki Sugahara** \\ *Kagawa Nutrition University, Institute of Nutrition Sciences, 3-9-21, Chiyoda, Sakado-shi, Saitama, \\ 350-02 \\ **Kagawa Nutrition University, 3-9-21, Chiyoda, Sakado-shi, Saitama, 350-02 \\ ***Kagawa Nutrition Junior College, 3-24-3, Komagome, Toshima-ku, Tokyo, 170 \\ $*, * *$ 个350-02 埼玉県坂戸市千代田 3-9-21 \\ *** $\mathbf{T} 170$ 東京都豊島区駒込 $3-24-3$
}

We investigated quantitatively the difference of the external shapes (weight, size), free amino acids and lentinic acid in six different varieties(Donko type ; Jyōdonko, Namidonko, Kotsubudonko, Köshin type ; Jyōkōshin, Namikōshin, Chayori) of dried Shiitake mushroom which were collected during 1983 1990 from Shizuoka, Ohita and Miyazaki prefectures. There was a difference in the total weight, cap weight and cap diameter among the varieties and were grouped into Donko and Köshin by the $\mathrm{F}$ value calculated for the rate of cap diameter per cap thickness. The amount of free amino acids were in the range of 2,395 2,732mg, with an average of $2,600 \mathrm{mg}$ for Donko and in the range of 2, 450 2,796mg, with an average of $2,565 \mathrm{mg}$ for Koshin, with no significant differences beings seen among the varieties. The main free amino acids were glutamine, glutamic acid, arginine, asparagine, alanine and ornithine and the similarity index for amino acid pattern calculated by the Tamura method showed close similarities among the six varieties. The amount of lentinic acid was in the range of $903 \sim 1,156 \mathrm{mg}$, with an average of 1,025mg for Donko and in the range of $820 \sim$ $1,000 \mathrm{mg}$, with an average of $899 \mathrm{mg}$ for Köshin, showing a difference between Donko and Kōshin types.

1983から1990年にわたり静岡県, 大分県, 宮崎県から収集した干しシイタケの 2 系統 6 銘柄 (冬 菇系; 上冬菇, 並冬菇, 小粒冬菇, 香信系; 上香信, 並香信, 茶撰) について, 形状（重量, 大き さ), 遊離アミノ酸およびレンチニン酸含有量を測定し, 銘柄間の差異を検討した. 総重量, 菌傘 部重量拉よび菌傘の直径は銘柄間に差異があり, 菌傘の厚さに対する菌傘の直径の割合から求めた $\mathrm{F}$ 值により冬菇系と香信系とに大別された。総遊離アミノ酸含有量は冬菇系では2, 395 2, 732 mg の範囲で, その平均は2, 600 mg, 香信系では2, 450 2, 796mgの範囲で, その平均は $2,565 \mathrm{mg}$ であ り, 銘柄間に有意差はなかった. 主要な遊離アミノ酸はグルタミン, グルタミン酸, アルギニン, アスパラギン, アラニン, オルチニンであり, 田村らの方法により求めたアミノ酸類似率は 6 銘柄 


\section{日本食生活学会誌}

間で極めて類似していた。レンチニン酸含有量は冬菇系では $903 \sim 1,156 \mathrm{mg}$ 範囲で，その平均は $1,025 \mathrm{mg}$ ，香信系では819 1,000mgの範囲で，その平均は $899 \mathrm{mg}$ であり，冬菇系と香信系との間 に差異がみられた.

\section{緒言}

近年,「健康食品」や「自然食品」などへの関心の高 まりに沿ってキノコ類の需要は大幅に増加している1). その中にめって，干しシイタケは古くから日本の食生活 と深く関わってきており依然需要の高い食品である。そ つ干しシイタケの品質については内地取引規格2), 輸出 票準規格3)，日本農林規格4)などにより開傘の程度，傘 つ大きさ, 色沢, 虫害の有無, 乾燥の程度により評価し 各種銘柄に分け，それぞれ価格がつけられて取り引きさ れている。しかしながら，我が国の干しシイタケの多く はコナラやクヌギなどの原木を用いて栽培したシイタケ を乾燥して生産されて扣り，栽培方法が自然に近く，こ のため天候条件などに左右されやすいことから，同一の 銘柄の干しシイタヶでも収穫年度や生産地によりその品 質は必ずしも一定ではない。

干しシイタケの各種銘柄品について，その品質を検討 した研究は少ない。これまで著者らは大分県産の干しシ イタケについて1970年から74年の 4 年間にわたり収集し た各種銘柄別の形状（重量, 菌傘の直径, 厚さ）, 遊離 アミノ酸扣よび水で加熱後の 5'-GMP含有量5) と1976 年産の試料について遊離糖および有機酸含有量 6 ）を報告 してきた. 今回は 1983 年から90年の 6 年間にわたり干し シイタケの国内の主要産地から銘柄別に収集してきた試 料について, 形状を測定し, また, 呈味に関与する主要 な成分の一つである遊離アミノ酸7) および香気成分のレ ンチオニンの前駆物質であるレンチニン酸含有量につい て測定した. 既報の結果と合わせ干しシイタケの品質に 関して検討したので報告する.

\section{実験方法}

分析に供した試料は $1983,84,87,88 ， 89 ， 90$ 年の静 岡県, 大分県, 宮崎県産の冬菇系（上冬菇, 並冬菇, 小 粒冬菇)，香信系（上香信，並香信，茶撰）の 2 系統 6 銘柄であり，全国椎茸商業協同組合連合会を通し直接各 県の生産者からそれぞれ $2 \mathrm{~kg}$ 以上を入手した。

\section{2. 方 法}

形状は各試料から無作為に10個を採り，総重量と菌柄 部を切断した菌金部重量を測定した．また菌金の直径抏 よび菌柄を取り除いた菌傘の中心部の厚さをキャリパー で測定した。

遊離アミノ酸およびレンチニン酸の抽出は佐藤ら ${ }^{8)}$ 抽 よび青柳ら ${ }^{9)}$ の方法に準じ, 試料 $0.5 \mathrm{~g}$ を70\%ェタノ一 ル溶液で加熱還流後, その抽出液を脱脂し, 次いでpH 2.2 クエン酸リチウム緩衝液で定容し，試験溶液とした。 日立835型高速アミノ酸自動分析計を用いて，非タンパ ク構成アミノ酸 11 種類を含む遊離アミノ酸 33 種類とレン チニン酸を定量した.

\section{結果と考察}

\section{1. 各種銘柄と形状}

各種銘柄の形状の測定結果をTable 1 に示した。総重 量と菌傘部重量はそれぞれ銘柄による差異がみられた が，総重量に対する菌傘部重量の割合は77.9〜 $82.0 \%$ で あり，銘柄間に大きな差異はなかった。菌傘の直径は小 粒冬菇の $31.0 \mathrm{~mm}$ か上香信の $77.2 \mathrm{~mm}$ をで銘柄間に大 きな差異がみられたが，菌金の厚さについては銘柄間の 差異は小さかった.

通常，菌傘の開いていないものを冬菇系，菌傘の開い ているものを香信系と区分しているが，松本ら10）の報 告を除いて明確な基準値は示されていない。そこで，松 本らにならい銘柄間に大きな差異がなかった菌傘の厚さ (h) に対する菌傘の直径（d）の割合（d/h）を求

\section{1. 試 料}

Table 1 External shapes of dried Shiitake mushrooms

\begin{tabular}{lllccr}
\hline Varieties & $\begin{array}{l}\text { Total } \\
\text { weight }(\mathrm{g})\end{array}$ & $\begin{array}{l}\text { Cap } \\
\text { weight }(\mathrm{g})\end{array}$ & $\begin{array}{l}\text { Cap } \\
\text { diameter }(\mathrm{mm})(\mathrm{d})\end{array}$ & $\begin{array}{l}\text { Cap } \\
\text { thickness }(\mathrm{mm})(\mathrm{h})\end{array}(\mathrm{d}) /(\mathrm{h})$ \\
\hline Jyō donko & $5.20 \pm 1.24$ & $4.22 \pm 1.08$ & $48.95 \pm 5.78$ & $6.89 \pm 1.60$ & 7.10 \\
Nami donko & $3.35 \pm 1.06$ & $2.61 \pm 0.84$ & $47.11 \pm 4.81$ & $6.38 \pm 3.77$ & 7.38 \\
Kotsubu donko & $1.74 \pm 0.48$ & $1.39 \pm 0.47$ & $31.04 \pm 3.49$ & $4.70 \pm 2.00$ & 6.60 \\
Jyō kōshin & $5.82 \pm 1.75$ & $4.77 \pm 1.54$ & $77.24 \pm 10.43$ & $6.87 \pm 2.48$ & 11.24 \\
Nami kōshin & $3.29 \pm 1.46$ & $2.68 \pm 1.07$ & $61.31 \pm 10.39$ & $5.48 \pm 1.80$ & 11.18 \\
Chayori & $3.24 \pm 0.90$ & $2.60 \pm 0.73$ & $55.88 \pm 6.68$ & $5.70 \pm 1.74$ & 9.80 \\
\hline
\end{tabular}

"Values are the means \pm S. D. of 160 measurements on dried Shiitake mushrooms harvested from Shizuoka, Ohita and Miyazaki prefectures during 1983 1990. 
めてみると冬菇系で6. 6 7. 4, 香信系で9. 8 11.2であ った.ささに, 上級品とされる上冬菇の值 $\left(\mathrm{d}_{\mathrm{o}} / \mathrm{h}_{\mathrm{o}}\right)$ に対 する他の銘柄の值 $\left(\mathrm{d}_{\mathrm{i}} / \mathrm{h}_{\mathrm{i}}\right)$ の割合 $\left[\left(\mathrm{d}_{\mathrm{i}} / \mathrm{h}_{\mathrm{i}}\right) /\left(\mathrm{d}_{\mathrm{o}} / \mathrm{h}_{\mathrm{o}}\right)\right.$; 以下 $\mathrm{F}$ 值と表するを求めてみると Fig. 1 亿示すよらに冬菇 系0.9〜1.0と香信系1.4〜1.6に大別が可能であった. ま た，既報5）の大分県産の 4 年分の試料を加えた10年間分 について求めてみると, 菌傘の厚さに対する菌金の直径 の割合 $(\mathrm{d} / \mathrm{h})$ は冬菇系では4.7〜6.3, 香信系では7.4 $\sim 10.0, \mathrm{~F}$ 值は冬菇系 $0.9 \sim 1.2$, 香信系 $1.4 \sim 1.9$ となり, 多少の変動はみられるが, F 值として算出される値は「開 傘の度合い」を示す尺度の一つとなり, 選別された上冬

Table 2 Free amino acids content in dried shiitake mushroom (Donko type)*

(mg/100g in dry matter)

\begin{tabular}{|c|c|c|c|}
\hline & Jyō Donko & Nami Donko & Kotsubu Donko \\
\hline Asp & $93.3 \pm 30.3$ & $82.9 \pm 20.3$ & $78.3 \pm 26.6$ \\
\hline Thr & $96.0 \pm 37.0$ & $108.5 \pm 28.6$ & $82.0 \pm 30.1$ \\
\hline Ser & $56.2 \pm 20.3$ & $65.2 \pm 16.8$ & $.51 .3 \pm 15.6$ \\
\hline Asn & $154.5 \pm 181.7$ & $106.4 \pm 37.3$ & $94.9 \pm 24.7$ \\
\hline Glu & $540.0 \pm 159.5$ & $523.0 \pm 112.3$ & $498.4 \pm 144.0$ \\
\hline Gln & $640.4 \pm 329.6$ & $663.4 \pm 256.1$ & $639.3 \pm 317.1$ \\
\hline Pro & $31.7 \pm 22.4$ & $32.4 \pm 15.1$ & $22.9 \pm 15.9$ \\
\hline Gly & $48.4 \pm 20.2$ & $50.8 \pm 17.2$ & $34.8 \pm 11.4$ \\
\hline Ala & $130.4 \pm 36.6$ & $115.8 \pm 30.8$ & $115.8 \pm 40.5$ \\
\hline Val & $40.7 \pm 16.6$ & $44.3 \pm 13.4$ & $31.6 \pm 13.0$ \\
\hline Cys & $1.5 \pm \quad 5.3$ & $0.3 \pm \quad 0.7$ & $3.0 \pm 5.7$ \\
\hline Met & $4.9 \pm \quad 4.2$ & $4.8 \pm$ & $5.1 \pm$ \\
\hline Ile & $27.6 \pm 12.5$ & $29.7 \pm \quad 9.5$ & $23.1 \pm 8.9$ \\
\hline Leu & $43.0 \pm 16.2$ & $46.6 \pm 12.8$ & $35.7 \pm 11.6$ \\
\hline Tyr & $49.7 \pm 20.6$ & $52.9 \pm 18.0$ & $38.4 \pm 15.9$ \\
\hline Phe & $48.3 \pm 18.7$ & $54.4 \pm 12.9$ & $38.1 \pm 10.4$ \\
\hline Trp & $31.4 \pm 11.4$ & $33.8 \pm 9.3$ & $25.7 \pm 10.2$ \\
\hline Lys & $94.5 \pm 41.3$ & $101.4 \pm 24.7$ & $76.9 \pm 27.4$ \\
\hline His & $48.4 \pm 17.8$ & $47.5 \pm 12.6$ & $35.1 \pm 12.0$ \\
\hline Arg & $151.7 \pm 65.2$ & $158.7 \pm 61.0$ & $141.2 \pm 58.1$ \\
\hline $\operatorname{Sar}^{1}$ & $29.1 \pm 95.5$ & $41.4 \pm 117.5$ & \\
\hline$\alpha-\mathrm{Aaa}^{2}$ & $0.6 \pm \quad 1.6$ & $2.0 \pm 3.8$ & $3.0 \pm 8$. \\
\hline $\mathrm{Cit}^{3}$ & $0.9 \pm 1.7$ & $1.2 \pm 2.1$ & $4.1 \pm 10.2$ \\
\hline$\alpha-\mathrm{Aba}^{4}$ & $1.1 \pm 1.6$ & $0.8 \pm$ & $0.7 \pm 1$ \\
\hline Cysthi $^{5}$ & $17.0 \pm \quad 7.5$ & $21.1 \pm 9.3$ & $14.0 \pm 7$. \\
\hline$\beta-\mathrm{Ala}^{6}$ & $35.5 \pm 27.9$ & $45.7 \pm 25.8$ & $33.0 \pm 16$. \\
\hline$\beta$-Abiba ${ }^{7}$ & $31.2 \pm 21.8$ & $41.0 \pm 20.4$ & $29.3 \pm 16$. \\
\hline$\gamma-\mathrm{Aba}^{8}$ & $68.0 \pm 43.1$ & $45.0 \pm 21.6$ & $73.5 \pm 51$ \\
\hline Orn $^{9}$ & $153.4 \pm 82.6$ & $208.6 \pm 90.7$ & $161.2 \pm 82$. \\
\hline 1 Mehis $^{10}$ & $0.4 \pm 0.8$ & $0.3 \pm 0.6$ & $2.1 \pm 6$ \\
\hline 3 Mehis $^{11}$ & $2.9 \pm \quad 2.6$ & $2.7 \pm \quad 2.2$ & $2.3 \pm 2$. \\
\hline Total & $2672.6 \pm 828.1$ & $2732.3 \pm 585.4$ & $2394.7 \pm 597$ \\
\hline
\end{tabular}

1 : Sarcosine, ${ }^{2}: \alpha$-Aminoadipic acid,

${ }^{3}:$ Citrulline, ${ }^{4}: \alpha$-Amino-n-butyric acid,

5 : Cystathionine, $6: \beta$-Alanine

$7: \beta$-Aminoisobutyric acid,

$8: \gamma$-Amino-n-butyric acid, ${ }^{9}:$ Ornithine,

$10: 1$-Methylhistidine, $11: 3$-Methylhistidine

"Values are the means \pm S. D. of 16 measurements on dried

Shiitake mushrooms harvested from Shizuoka, Ohita and Miyazaki prefectures during $1983 \sim 1990$.
Fig. 1 Clssification of dried Shiitake mushrooms according to size of cap.

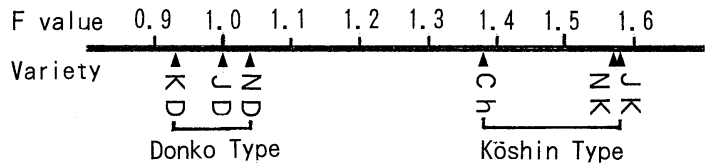

$\mathrm{F}=\left(\mathrm{d}_{\mathrm{i}} / \mathrm{h}_{\mathrm{i}}\right) /\left(\mathrm{d}_{\mathrm{o}} / \mathrm{h}_{\mathrm{o}}\right): \mathrm{d}_{\mathrm{i}} ;$ cap diameter, $\mathrm{h}_{\mathrm{i}} ;$ cap thickness, $\mathrm{d}_{\mathrm{o}} ;$ cap diameter of JD, $h_{0}$; cap thickness of JD.

Abbreviations are as follows : JD ; Jyödonko, ND ; Namidonko, KD ; Kotsubu donko, JK ; Jyōkōshin, NK ; Namiköshin, Ch ; Chayori

Table 3 Free amino acids content in dried shiitake mushroom (Kōshin type)

$(\mathrm{mg} / 100 \mathrm{~g}$ in dry matter $)$

\begin{tabular}{|c|c|c|c|}
\hline & Jyō Kōshin & Nami Kōshin & Chayori \\
\hline Asp & $69.4 \pm 25.6$ & $71.4 \pm 21.1$ & $78.1 \pm 23.3$ \\
\hline Thr & $95.4 \pm 32.3$ & $96.6 \pm 32.4$ & $109.5 \pm 35.5$ \\
\hline Ser & $65.9 \pm 23.3$ & $74.0 \pm 24.9$ & $75.4 \pm 27.0$ \\
\hline Asn & $109.2 \pm 40.3$ & $118.7 \pm 38.5$ & $117.9 \pm 47.6$ \\
\hline Glu & $456.1 \pm 149.0$ & $433.5 \pm 111.3$ & $507.4 \pm 147.0$ \\
\hline Gln & $539.9 \pm 228.2$ & $552.7 \pm 226.9$ & $685.3 \pm 252.9$ \\
\hline Pro & $31.8 \pm 12.3$ & $28.3 \pm 14.2$ & $29.6 \pm 16.7$ \\
\hline Gly & $46.5 \pm 17.1$ & $43.5 \pm 15.2$ & $48.1 \pm 15.2$ \\
\hline $\mathrm{Ala}$ & $105.5 \pm 28.8$ & $106.3 \pm 30.5$ & $115.8 \pm 25.1$ \\
\hline Val & $48.9 \pm 26.0$ & $40.3 \pm 12.8$ & $44.8 \pm 16.7$ \\
\hline Cys & $3.5 \pm 11.0$ & $3.3 \pm 6.8$ & $0.8 \pm \quad 1.6$ \\
\hline Met & $4.5 \pm 3.9$ & $4.8 \pm \quad 3.5$ & $3.9 \pm 2.8$ \\
\hline Ile & $28.2 \pm 11.7$ & $26.2 \pm 10.7$ & $27.5 \pm 10.6$ \\
\hline Leu & $43.5 \pm 16.0$ & $43.6 \pm 14.7$ & $45.2 \pm 14.9$ \\
\hline Tyr & $45.7 \pm 16.3$ & $54.1 \pm 20.7$ & $52.8 \pm 21.7$ \\
\hline Phe & $50.4 \pm 17.8$ & $49.1 \pm 13.3$ & $53.6 \pm 16.8$ \\
\hline Trp & $34.0 \pm \quad 8.6$ & $31.1 \pm 8.0$ & $34.3 \pm 8.5$ \\
\hline Lys & $87.7 \pm 25.4$ & $86.5 \pm 26.6$ & $96.9 \pm 37.5$ \\
\hline $\mathrm{His}$ & $38.1 \pm 15.4$ & $37.3 \pm 12.0$ & $42.8 \pm 16.4$ \\
\hline Arg & $132.8 \pm 43.4$ & $138.6 \pm 61.6$ & $150.1 \pm 69.6$ \\
\hline $\operatorname{Sar}^{1}$ & $19.4 \pm 75.0$ & $17.6 \pm 68.1$ & $46.4 \pm 119.6$ \\
\hline$\alpha-\mathrm{Aaa}^{2}$ & $0.6 \pm 1.6$ & $0.5 \pm \quad 1.2$ & $0.9 \pm 2.1$ \\
\hline $\mathrm{Cit}^{3}$ & $1.0 \pm 1.8$ & $0.5 \pm$ & $1.6 \pm$ \\
\hline$\alpha-\mathrm{Aba}^{4}$ & $1.7 \pm 5.0$ & $1.4 \pm$ & $1.1 \pm$ \\
\hline Cysthi ${ }^{5}$ & $16.7 \pm 8.8$ & $17.6 \pm 8.1$ & $17.9 \pm 5.5$ \\
\hline$\beta-\mathrm{Ala}^{6}$ & $48.2 \pm 26.8$ & $42.1 \pm 23.4$ & $44.0 \pm 29.4$ \\
\hline$\beta-\mathrm{Abiba}^{7}$ & $42.0 \pm 15.8$ & $39.2 \pm 21.1$ & $39.4 \pm 26.2$ \\
\hline$\gamma-\mathrm{Aba}^{8}$ & $64.0 \pm 49.8$ & $58.2 \pm 35.9$ & $57.0 \pm 39.7$ \\
\hline Orn $^{9}$ & $216.6 \pm 112.9$ & $227.4 \pm 117.4$ & $263.5 \pm 118.7$ \\
\hline 1 Mehis $^{10}$ & $2.3 \pm 6.8$ & $1.3 \pm 2.1$ & $1.2 \pm 1.4$ \\
\hline 3 Mehis $^{11}$ & $3.0 \pm 2.7$ & $2.2 \pm 1.8$ & $2.6 \pm 2.1$ \\
\hline
\end{tabular}

"Abbrevations and values are the same as those of Table 2 . 
日本食生活学会誌

菇を基準に「開傘の度合い」による各銘柄の区分が可能 であると思われる。

\section{2. 各種銘柄と遊離アミノ酸含有量について}

遊離アミノ酸の測定結果をTable 2,3 亿示した。総 遊離アミノ酸含有量は無水物 $100 \mathrm{~g}$ 当たり, 冬菇系では $2,395 \sim 2,732 \mathrm{mg}$ の範囲で, その平均は $2,600 \mathrm{mg}$, 香信 系では $2,450 \sim 2,796 \mathrm{mg}$ の範囲で, その平均は $2,565 \mathrm{mg}$ であった．冬菇系の方がやや高い值であったが，小粒冬 菇を除くと各銘柄間に有意差はなかった。 また，各銘柄 とも主要な遊離アミノ酸はタンパク構成アミノ酸のグル タミンとグルタミン酸であり, 両者で総含有量の $40 \%$ 以 上を占め, 次いでアルギニン, アスパラギン, アラニン, 非タンパク構成アミノ酸のオルニチンなどであった. 遊 離アミノ酸組成の比較のため田村ら ${ }^{11)}$ の方法により上 冬菇を 1 として各銘柄の「アミノ酸パターン類似率」を 求め, その結果をTable 4 亿示した. 表にみられるよら に0.9961〜0.9865であり, 銘柄間に組成の差異は汪とん ど認められなかった. 既報5)ではアミノ酸分析計の性能 からスレオニン・セリン・グルタミン・アスパラギンの 正確な分離ができないためこれらを一括した量で示した が，各銘柄ともアミノ酸構成は今回と同様の傾向を示し ていた.

Table 4 Similarity for amino acid pattern among the varieties*

\begin{tabular}{lc}
\hline Varieties & Similarity \\
\hline Jyō donko & 1.0000 \\
Nami donko & 0.9942 \\
Kotsubu donko & 0.9961 \\
Jyō kōshin & 0.9920 \\
Nami koshin & 0.9911 \\
Chayori & 0.9865 \\
\hline
\end{tabular}

*The similarity for amino acid pattern was calculated by the Tamura method.

\section{3. 各種銘柄とレンチニン酸含有量について}

レンチニン酸の測定結果をTable 5 と示した. 含有量 は無水物 $100 \mathrm{~g}$ 当たり, 冬菇系では $903 \sim 1,156 \mathrm{mg}$ の範囲 で, その平均は $1,025 \mathrm{mg}$, 香信系では $819 \sim 1,000 \mathrm{mg}$ の 範囲で, その平均は $899 \mathrm{mg}$ であり, やや冬菇系の方が高 い傾向汹めった。

最近，市場には菌床栽培によって得られた生シイタケ を乾燥した干しシイタケ，例宎ば中国産のものが散見さ れる.これらのものの F值は1.03 $(\mathrm{n}=9)$ で冬菇系に 区分される形状であるが, 総遊離アミノ酸含有量は $1779.7 \mathrm{mg}$ と低く, 国内産の原木栽培のものとの遊離ア
Table 5 Lentinic acid content of in dried Shiitake mushrooms

(mg/100g in dry matter)

\begin{tabular}{lr}
\hline Varieties & Lentinic Acid \\
\hline Jyo Donko & $1,016 \pm 263$ \\
Nami Donko & $1,156 \pm 439$ \\
Kotsubu Donko & $903 \pm 263$ \\
Jyo Koshin & $878 \pm 359$ \\
Nami Koshin & $820 \pm 394$ \\
Chayori & $1,000 \pm 321$ \\
\hline
\end{tabular}

"Values are the same as those of Table 2.

ミノ酸パターン類似率も0.9025とシイタケの中では低 く, 組成に違いがみられる ケに括いても原木栽培と菌床栽培のものとでは遊離アミ ノ酸の含有量および組成に差が認められて扣り13), 菌床 栽培のものを類別することが可能であると思われる. し かし, 干しシイタケの品質, 特に内部特性としての化学 的成分については今後とも多面的に検討する必要があ る.

$$
\text { まとめ }
$$

静岡県, 大分県, 宮崎県から1983から1990年の 6 年間 にわたり収集した干しシイタケの 2 系統 6 銘柄（冬菇 系; 上冬菇, 並冬菇, 小粒冬菇, 香信系; 上香信, 並香 信, 茶撰) について, 形状, 遊離アミノ酸拉よびレンチ ニン酸含有量を測定し，銘柄間の差異を検討した。

1）総重量, 菌傘部重量, 菌傘の直径は銘柄間に差 異がみられた. 菌傘の厚さ $(\mathrm{h})$ に対する菌傘の直径 $(\mathrm{d})$ の割合 $(\mathrm{d} / \mathrm{h})$ を求め, さらに上冬菇の值 $\left(\mathrm{d}_{\mathrm{o}} / \mathrm{h}_{\mathrm{o}}\right)$ に 対する他の銘柄の值 $\left(\mathrm{d}_{\mathrm{i}} / \mathrm{h}_{\mathrm{i}}\right)$ の割合 $\left(\mathrm{d}_{\mathrm{i}} / \mathrm{h}_{\mathrm{i}}\right) /\left(\mathrm{d}_{\mathrm{o}} / \mathrm{h}_{\mathrm{o}}\right)(\mathrm{F}$ 值と表す）は「開傘の度合い」を示す指標となり, 明確 に冬菇系と香信系とを大別することが可能であった.

2）総遊離アミノ酸含有量特よび組成は銘柄間飞明 確な差異は認められなかった。

3）レンチニン酸含有量は銘柄間の差異は小さいが 冬菇系の方がやや高い傾向を示した.

終わりに試料を提供された全国椎茸商業共同組合連合 会の原洋一氏ならびに実験に協力された大日方真奈美, 崎村佳世, 土屋由美子, 鳥飼治美, 新津真紀, 沼里正美, 沼田登志子, 横山智子の諸氏に深く感謝いたします。

\section{参 考 文 献}

1）農村文化社「きのこ年鑑」編集部：「’96年版きのこ年鑑」, 農村文化社 (1995)

2）日本椎茸農業協同組合連合会：内地取引規格 
3）農林省·通産省令 4 号 : 輸出検査法, 昭和 46 年

4）農林省告示第 730 号 : 日本農林規格, 昭和 33 年

5）菅原龍幸・新井静子・青柳康夫・国崎直道：栄責と食糧, 28, 477 (1975)

6）吉田博・菅原龍幸・林淳三：日食工誌，28，356（1979）

7）佐々木弘子: 女子栄養大学栄養科学研究所年報, 4, 63, (1996)

8）佐藤恵理 - 青柳康夫 - 菅原龍幸：日食工誌， 32 , 509 (1985)
9）青柳康夫・佐々木弘子・菅原龍幸：農化，54，253（1980）

10）松本仲子 · 青柳康夫 · 平野雄一郎 · 菅原龍幸 : 日食工誌, 25, 129 (1978)

11）田村真八郎 · 大沢文江：栄養と食糧，22，494（1969）

12）菅原龍幸・佐々木弘子・青柳康夫 : 日本食品工業学会第 35回大会口頭発表, (1988)

13）菅原龍幸 - 奥崎政美 - 青柳康夫 - 佐々木弘子 : 日本食品 科学工学会第42回大会口頭発表, (1995) 